\title{
On-line SPE-HPLC Method using Alumina Filtering to Selectively Extract Phenolic Compounds from Environmental Water
}

\author{
Sung Kwang Lee \\ Department of Chemistry, Hannam University, Daejeon 305-811, Korea.E-mail: leesk@hnu.kr \\ Received October 6, 2010, Accepted October 26, 2010
}

\begin{abstract}
A on-line SPE (solid phase extraction)-HPLC preconcentration method was developed for the determination of phenolic compounds at trace levels in environmental water sample. XAD-4 and Dowex 1-X8 were used as sorbent in the on-line SPE-HPLC method for the selective enrichment of nine phenolic compounds, which are included in the priority pollutants list of the US EPA. Also alumina prefiltering considerably reduced the amount of interfering peaks due to humic substances that could accumulated due to the preconcentration step and prevent quantification of polar phenolic compounds in environmental water samples. This method was used to determine the phenolic compounds in tap and river water and superiority to the US EPA 625 method in its enrichment factor, pretreatment time, recoveries, and detection limit. The limits of detection were in the range of $0.3-0.9 \mu \mathrm{g} / \mathrm{L}$ in tap water sample.
\end{abstract}

Key Words: Phenols, Solid phase extraction, On-line SPE-HPLC system, Alumina filtering, Humic substances

\section{Introduction}

Phenolic compounds, which mainly come from many drug, textiles, dyes, pesticides, pulp, and paper manufacturing processes are widespread industrial waste contaminants. ${ }^{1}$ Due to their toxicity and persistence in the environment, some of the phenols have been included in the US EPA (Environmental Protection Agency) list of priority pollutants. ${ }^{2}$ EU Directive 2455/ 2001/EC states that the total concentration of phenolic compounds should be below $0.5 \mathrm{ppb}$ and their individual concentrations should not exceed $0.1 \mathrm{ppb}$ in drinking water. ${ }^{3}$

For the quantitative sub-ppb analysis of phenolic compounds in environmental waters, liquid chromatography (LC) combined with sample preconcentration are generally used. Although the current official preconcentration method for phenolic compounds is liquid-liquid extraction (LLE) (US EPA Methods $604,625),{ }^{4,5}$ there is a tendency to use a solid-phase extraction $(\mathrm{SPE})^{6-8}$ method which has advantages with regard to time and solvent saving over LLE. The SPE method, which has been rapidly developing for 30 years, is used as powerful sample pretreatment method because it can be easily automated and its partition coefficient and sample throughput are high in comparison with the LLE method.

A SPE precolumn is frequently coupled on-line to GC, HPLC and $\mathrm{CE}$ for environmental and biomedical analysis ${ }^{9,10}$ because it allows for minimizing of sample handling and contamination and it improves reproducibility. Highly cross-linked polymer resins are sorbents that are more commonly used than $\mathrm{C}_{18}$ chemically bonded silica owing to their good recoveries for phenolic compounds which differ widely in polarity. ${ }^{11}$ When such sorbent is used in the on-line SPE method for environmental water samples, broad initial bands arise from the coextracted humic substance (humic and fulvic acids). This bands prevent the quantification of polar phenolic compounds that eluted early in the reversed phase liquid chromatography. ${ }^{12}$

In this study, on-line SPE-HPLC system, which allows sample injection via the on-line connecting of SPE precolumns with an HPLC analytical column, was developed for the pretreatment of phenolic compounds in environmental water samples. Amberlite XAD-4 and Dowex 1-X8 parallel columns were used for preconcentration and an acidic alumina was used as a prefilter to reduce the initial bands due to humic substance in the environmental sample. This method was compared with the US EPA 625 (acid-extractable section) method in terms of recoveries, reproducibility, and detection limit of samples.

\section{Experimental}

Instrumentation. The chromatographic system included a Model 45 pump, Model 440 fixed-wavelength (280 nm) absorbance detector, U6K sample injector (all from Waters Associates, Milford, MA, USA), and a Shimadzu (Kyoto, Japan) CR6A integrator. A ten-port C10W valve (Valco, Houston, TX, USA), a six-port stream selection V240 valve (Upchurch, Oak Harbor, WA, USA), and a six-port Rheodyne 7000 valve (Rheodyne, Inc., Cotati, CA, USA) were used for the on-line system (Fig. 1).

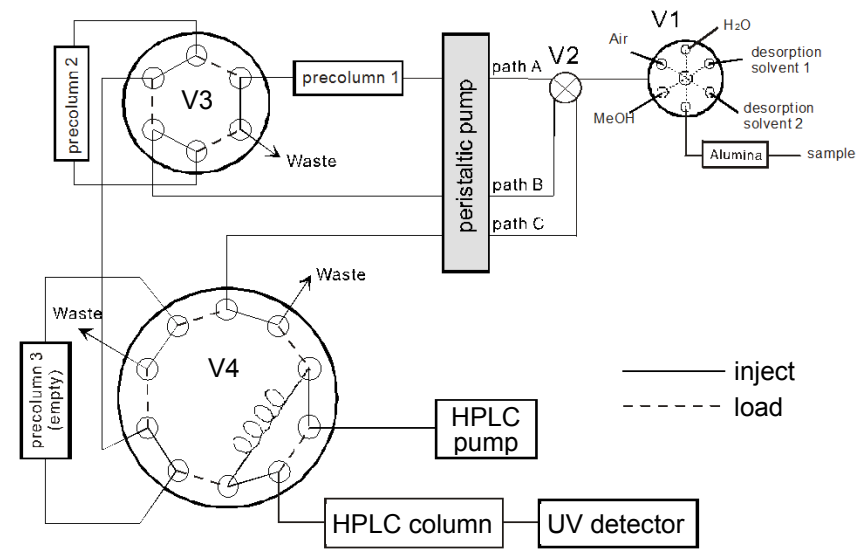

Figure 1. The schematic diagram of the on-line SPE-HPLC system for phenolic compounds. Precolumn 1: XAD-4 column; precolumn 2: Dowex 1-X8 column; precolumn 3: empty column; V1: 6-ports stream valve; V2: 4-way selection valve; V3: 6-ports switching valve; V4: 10-ports switching valve; desorption solvent 1: $90 \% \mathrm{ACN}(\mathrm{pH} 12.5)$; desorption solvent 2: $0.5 \mathrm{M} \mathrm{HCl}$ (in $\mathrm{MeOH}$ ). 
Table 1. The preconcentration procedure using the on-line SPE-HPLC system

\begin{tabular}{|c|c|c|c|c|c|}
\hline \multirow{2}{*}{ Step } & \multirow{2}{*}{ Operation } & \multicolumn{4}{|c|}{ Valve position } \\
\hline & & $\mathrm{V} 1$ & $\mathrm{~V} 2$ & V3 & V4 \\
\hline 1 & $\begin{array}{l}\text { Precolumn } 1(50 \mathrm{~mm} \times 3 \mathrm{~mm} \text { i.d., slurry-packed, XAD- } 4 \text { resin) are cleaned and condi- } \\
\text { tioned with } 10 \mathrm{~mL} \text { of } \mathrm{MeOH} \text { and with } 20 \mathrm{~mL} \text { of LC-grade water at the rate of } 3 \mathrm{~mL} / \mathrm{min} \text {. }\end{array}$ & $\begin{array}{c}\mathrm{MeOH} \\
\mathrm{H}_{2} \mathrm{O}\end{array}$ & path A & inject & inject \\
\hline 2 & $\begin{array}{l}\text { Precolumn } 2(20 \mathrm{~mm} \times 3 \mathrm{~mm} \text { i.d., slurry-packed, Dowex } 1-\times 8 \text { resin }) \text { are cleaned and } \\
\text { conditioned with } 10 \mathrm{~mL} \text { of } \mathrm{MeOH}, 20 \mathrm{~mL} \text { of } 1 \mathrm{M} \mathrm{NaOH} \text { in water and then with } 20 \mathrm{~mL} \\
\text { of LC-grade water at the rate of } 3 \mathrm{~mL} / \mathrm{min} \text {. }\end{array}$ & $\begin{array}{l}\mathrm{MeOH} \\
\mathrm{M} \mathrm{NaOH} \\
\mathrm{H}_{2} \mathrm{O}\end{array}$ & path B & inject & inject \\
\hline 3 & $\begin{array}{l}\text { Sample solution via alumina prefilter are introduced onto precolumn } 1 \text { at the rate of } 3 \\
\mathrm{~mL} / \mathrm{min} \text {. }\end{array}$ & Sample & path A & inject & inject \\
\hline 4 & $\begin{array}{l}\text { Precolumn } 1 \text { are rinsed with } 12 \mathrm{~mL} \text { of water at the rate of } 3 \mathrm{~mL} / \mathrm{min} \text { and air-dried } \\
\text { for } 0.5 \mathrm{~min} \text {. }\end{array}$ & $\mathrm{H}_{2} \mathrm{O}$ & path A & inject & inject \\
\hline 5 & $\begin{array}{l}\text { Desorption of analyte from precolumn } 1 \text { to precolumn } 2 \text { are performed with } 3 \mathrm{~mL} \text { of } \\
90 \% \text { ACN }(\mathrm{pH} 12.5) \text { at the rate of } 0.5 \mathrm{~mL} / \mathrm{min} \text {. }\end{array}$ & $\begin{array}{l}90 \% \mathrm{ACN} \\
(\mathrm{pH} 12.5)\end{array}$ & path A & load & inject \\
\hline 6 & Precolumn 2 are rinsed with $3 \mathrm{~mL}$ of water and air-dried for $0.5 \mathrm{~min}$. & $\mathrm{H}_{2} \mathrm{O}$ & path A & load & inject \\
\hline 7 & $\begin{array}{l}\text { Backflush desorption from precolumn } 2 \text { are perfomed with } 0.2 \mathrm{~mL} \text { of } 0.5 \mathrm{M} \mathrm{HCl} \text { in } \mathrm{MeOH} \\
\text { at the rate of } 0.05 \mathrm{~mL} / \mathrm{min} \text {. Desorbed solution are collected into empty precolumn } 3\end{array}$ & $\begin{array}{l}0.5 \mathrm{M} \mathrm{HCl} \\
\text { (in } \mathrm{MeOH})\end{array}$ & path B & inject & inject \\
\hline 8 & Precolumn 3 are air-bubbled to mix solution & Air & path B & inject & inject \\
\hline 9 & $\begin{array}{l}\text { Injection loop }(20 \mu \mathrm{L}) \text { are filled with the solution. } \\
\text { And solution are injected. }\end{array}$ & Air & path C & inject & $\begin{array}{l}\text { load } \\
\text { inject }\end{array}$ \\
\hline
\end{tabular}

On-line sample loading was performed with MasterFlex Microprocessor pump (Cole-Parmer, Chicago, IL, USA). The precolumn $1(50 \times 3 \mathrm{~mm}$ i.d. $)$ was filled manually with a Amberlite XAD-4 packing material and precolumn $2(20 \times 3 \mathrm{~mm}$ i.d. $)$ was filled manually with a Dowex 1-X8 anion exchange resin. LC-grade water was obtained by a Milli-Q system (Millipore, Bedford, MA, USA).

The on-line SPE-HPLC method was performed by using three precolumns, four switching valves, and an injector. The steps of the preconcentration procedure were schematically represented in Figure 1 and summarized in Table 1.

Reagents and standards. Phenolic compounds were first grade or reagent grade chemicals and purified by simple distillation or recrystalization. The nine phenolic compounds studied were as follows: phenol, $p$-nitrophenol, $o$-chlorophenol, o-nitrophenol, 2,4-dimethy-lphenol, 4-chloro- $m$-cresol, 4,6-dinitro-o-cresol, 2,4-dichlorophenol, and 2,4,6-trichloro-phenol. The individual stock standard solutions of all phenolic compounds were prepared in HPLC grade aqueous MeOH mixtures. The XAD-4 macroreticular resin was purchased from Rohm \& Haas (Philadelphia, PA, USA) and prepared by grinding and sieving (150 $200 \mathrm{mesh})$. The resins were purified by Soxhlet extractor using methanol and acetonitrile.

Mobile phase and stationary phase. Mixtures of water, methanol, and acetonitrile (Burdick \& Jackson Laboratories, Inc., Muskegon, MI, USA) were used as the mobile phase (50:28:22, $\mathrm{v} / \mathrm{v})$ : $\mathrm{pH}$ was adjusted to 3 using $99.9 \% \mathrm{H}_{3} \mathrm{PO}_{4}$. The mobile phase used was degassed by vacuum filtration through a $0.45 \mathrm{~m}$ nylon 66 filter (Alltech Associates, Deerfield, IL, USA) followed by agitation in ultrasonic bath. The flow rate of the mobile phase was $1.0 \mathrm{~mL} / \mathrm{min}$. A Shodex C18 column $(5 \mu \mathrm{m}, 250 \times$ $4.6 \mathrm{~mm}$ i.d. Showa Denko K.K., Tokyo, Japan) was used. The column was thermostatted at $30^{\circ} \mathrm{C}$ using a home-made water bath. The quantification was done by external calibration with standard solutions in $90 \% \mathrm{ACN}(\mathrm{pH} 12.5)$.
The EPA standard method ${ }^{5}$ was carried out to compare it with this study as follows. First, $500 \mathrm{~mL}$ of tap water was adjusted to $\mathrm{pH}=1.5$ with $\mathrm{H}_{2} \mathrm{SO}_{4}$ and spiked with a concentration of $5 \mathrm{ppb}$ for each analyte. The solution was transferred to a separatory funnel and extracted with $60 \mathrm{~mL}$ of methylene chloride three times. The collected methylene chloride solution was eluted on an anhydrous $\mathrm{Na}_{2} \mathrm{SO}_{4}$ column at $5 \mathrm{~mL} / \mathrm{min}$ to remove water. Eluate was evaporated on a $60-65{ }^{\circ} \mathrm{C}$ water bath with a $\mathrm{Ku}-$ derna-Danish concentrator. When $5 \mathrm{~mL}$ of solution remained, the flask was rinsed with a small amount of methylene chloride and the eluate was continued to be evaporated. After most of the solution was evaporated, the Kuderna-Danish tube was separated, up to $5 \mathrm{~mL}$ of methanol was added, $20 \mu \mathrm{L}$ of the solution was taken, and this solution was injected into HPLC.

\section{Results and Discussion}

Preconcentration. In the previous study, Lee et al. ${ }^{13}$ developed an on-line system for the preconcentration and separation of trace phenolic compounds by SPE-HPLC. They showed that the coupling of XAD-4 and Dowex 1-X8 resin increased the selectivities of phenolic compounds from added artificial interferences in pure water. On the basis of previous study, the system was applied to environmental samples such as tap and river water by optimizing the adsorption efficiency of the resin and by resolving the problem of quantification for determination of phenolic compounds. In order to improve the detection limit of the system and increase recoveries of phenolic compounds, the adsorption efficiency of the XAD-4 adsorbent were obtained according to the volume of water sample. Table 2 represents the mean recoveries of phenolic compounds spiked in tap water samples as function of the sample volume and particle size of the XAD-4 resin. It shows that the $150-200$ mesh XAD-4 resin is suitable for preconcentration without breakthrough of phenol at tap water sample volumes of up to $100 \mathrm{~mL}$. 
Table 2. Mean recoveries of phenolic compounds spiked in tap water samples as a function of the sample volume and particle sizes of $\mathrm{XAD}-4$ at $\mathrm{pH} 3$

\begin{tabular}{|c|c|c|c|c|}
\hline \multirow{3}{*}{ Compound } & \multicolumn{4}{|c|}{$\%$, Recovery $^{a} \pm \operatorname{SD}(\%)^{b}$} \\
\hline & \multicolumn{3}{|c|}{$40-100$ mesh } & \multirow{2}{*}{$\begin{array}{c}150-200 \\
\text { mesh }\end{array}$} \\
\hline & $25 \mathrm{~mL}$ & $50 \mathrm{~mL}$ & $100 \mathrm{~mL}$ & \\
\hline phenol & $95 \pm 3$ & $81 \pm 4$ & $74 \pm 4$ & $120 \pm 4$ \\
\hline$p$-nitrophenol & $101 \pm 3$ & $102 \pm 3$ & $106 \pm 4$ & $106 \pm 3$ \\
\hline$o$-chlorophenol & $100 \pm 2$ & $99 \pm 3$ & $96 \pm 3$ & $97 \pm 3$ \\
\hline$o$-nitrophenol & $99 \pm 6$ & $100 \pm 6$ & $104 \pm 6$ & $110 \pm 6$ \\
\hline 2,4-dimethylphenol & $99 \pm 5$ & $100 \pm 6$ & $99 \pm 6$ & $99 \pm 6$ \\
\hline 4-chloro- $m$-cresol & $93 \pm 4$ & $93 \pm 4$ & $91 \pm 4$ & $91 \pm 4$ \\
\hline 4,6-dinitro-o-cresol & $95 \pm 4$ & $94 \pm 4$ & $93 \pm 4$ & $93 \pm 4$ \\
\hline 2,4-dichlorophenol & $90 \pm 3$ & $90 \pm 4$ & $88 \pm 4$ & $90 \pm 4$ \\
\hline 2,4,6-trichlorophenol & $92 \pm 4$ & $89 \pm 4$ & $89 \pm 4$ & $93 \pm 4$ \\
\hline average & 96 & 94 & 93 & 100 \\
\hline
\end{tabular}

${ }^{a}$ Amount of each phenolic compound spiked in tap water: $0.5 \mu \mathrm{g}$. Sample $\mathrm{pH}$ was adjusted to 3 by $\mathrm{HCl}$. ${ }^{b} \mathrm{SD}$ : Standard deviation calculated from three measurements.

Effect of the sample pH adjusting agent. As most phenols are relatively acidic, the sample $\mathrm{pH}$ must be adjusted to lower the value to avoid deprotonation of the phenolic compounds on the nonpolar XAD-4 resin. It should be considered that the sample $\mathrm{pH}$ adjusting agent can influence the extraction efficiency for the Dowex 1-X8 precolumn by competing with counter ion on the anion exchange resin in spite of washing the XAD-4 precolumn (step 4 in Table 2). Table 3 shows the effect of the sample $\mathrm{pH}$ and $\mathrm{pH}$ adjusting agent on the recoveries of phenolic compounds. The best result was obtained at $\mathrm{pH} 3$ adjusted with $\mathrm{HCl}$. This optimal condition is related with the washing effect. The $\mathrm{Cl}^{-}$ion was more easily washed with water than $\mathrm{PO}_{4}{ }^{3-}$ in the washing step on the XAD-4 precolumn and it did not compete with the phenolic compounds for transferring from the XAD-4 to Dowex 1-X8 precolumn. Therefore, this difference in recoveries is attributed to possibility of analytes penetration through Dowex 1-X8 precolumn when they can be competed with counter anion in sample.

It is well known that the recoveries of samples adjusted to lower $\mathrm{pH}$ levels are higher due to the prevention of dissociation of more acidic compounds. ${ }^{14}$ However, when the $\mathrm{pH}$ of the sample solution was lower than 3 , as adjusted by $\mathrm{HCl}$, the mean recovery of phenolic compounds was lower than those of the $\mathrm{pH} 3$ samples. It is assumed that $\mathrm{Cl}^{-}$are not washed sufficiently when the concentration of $\mathrm{Cl}^{-}$is higher, and then the remaining $\mathrm{Cl}^{-}$compete with phenolic compounds on the Dowex 1-X8 column. This tendency was verified by the fact that the mean recovery of phenolic compounds decreased (to $70 \%$ ) when $0.01 \mathrm{M}$ $\mathrm{Na}_{3} \mathrm{PO}_{4}$ and $\mathrm{NaCl}$ were added to the sample solution. When the washing volume of pure water increased from $12 \mathrm{~mL}$ to 15 or $20 \mathrm{~mL}$, it was found that recovery of phenol decreased. This low recovery of phenol seems to be mainly due to its highest solubility in water (Table 3 ). Therefore, its volume of washing solution was fixed at $12 \mathrm{~mL}$.

Alumina clean up. The quantification of the polar phenolic
Table 3. Effect of sample $\mathrm{pH}$ and reagents on the recoveries of phenolic compounds in tap water samples

\begin{tabular}{|c|c|c|c|c|c|}
\hline \multirow{4}{*}{ Compound } & \multirow{4}{*}{$\mathrm{p} K_{\mathrm{a}}^{a}$} & \multirow{4}{*}{$\begin{array}{c}\text { Water }^{b} \\
\text { solubility } \\
(\mathrm{mg} / \mathrm{L})\end{array}$} & \multicolumn{3}{|c|}{$\%$, Recovery ${ }^{c} \pm \mathrm{SD}^{d}$} \\
\hline & & & \multicolumn{3}{|c|}{$\mathrm{pH}$ adjusting agent } \\
\hline & & & $\mathrm{H}_{3} \mathrm{PO}_{4}$ & \multicolumn{2}{|c|}{$\mathrm{HCl}$} \\
\hline & & & $\mathrm{pH}=3.0$ & $\mathrm{pH}=2.5$ & $\mathrm{pH}=3.0$ \\
\hline phenol & 9.99 & 82400 & $81 \pm 4$ & $77 \pm 4$ & $120 \pm 4$ \\
\hline$p$-nitrophenol & 7.16 & 11600 & $85 \pm 5$ & $107 \pm 5$ & $106 \pm 3$ \\
\hline$o$-chlorophenol & 8.55 & 11300 & $79 \pm 4$ & $101 \pm 4$ & $97 \pm 3$ \\
\hline$o$-nitrophenol & 7.21 & 2500 & $97 \pm 6$ & $105 \pm 6$ & $110 \pm 6$ \\
\hline 2,4-dimethylphenol & 10.6 & 7870 & $74 \pm 6$ & $76 \pm 5$ & $99 \pm 6$ \\
\hline 4-chloro- $m$-cresol & 9.55 & 3830 & $65 \pm 4$ & $69 \pm 4$ & $91 \pm 4$ \\
\hline 4,6-dinitro-o-cresol & 4.34 & 198 & $78 \pm 4$ & $86 \pm 4$ & $93 \pm 4$ \\
\hline 2,4-dichlorophenol & 7.85 & 4500 & $69 \pm 5$ & $86 \pm 5$ & $90 \pm 4$ \\
\hline 2,4,6-trichlorophenol & 7.42 & 800 & $61 \pm 4$ & $82 \pm 4$ & $93 \pm 4$ \\
\hline average & & & 77 & 88 & 100 \\
\hline
\end{tabular}

$\overline{\mathrm{p}} K_{\mathrm{a}}$ values were taken from ref $14 .{ }^{b}$ All water solubility data were obtained from PhysProp database ( $\mathrm{ref} 15$ ). ${ }^{b}$ Concentration of each compound spiked in tap water : $0.5 \mu \mathrm{g} / 100 \mathrm{~mL}$. ${ }^{.} \mathrm{SD}$ : Standard deviation calculated from three measurements.

compounds in tap and environmental water samples remains difficult because of the highly drifted and interfering matrix peaks in the LC. Owing to overlap of the broad interfering peaks with peaks of polar phenolic compounds, recoveries of over $100 \%$ were found for their compounds, such as phenol, p-nitrophenol and o-nitrophenol. It is well known that this is due to the presence of humic substance that elute early in reversed phase LC by acidification of the water sample. ${ }^{16}$ As humic substances, such as humic and fulvic acid, are similar to phenolic compounds in terms of having nonpolar and anionic fragments, it was difficult to selectively extract the phenolic compounds from the humic substance using only the XAD-4 and Dowex 1-X8 precolumns. Masque and co-workers ${ }^{17-18}$ added sodium sulfite to decrease the initial broad peaks due to fulvic and humic acids in the $\mathrm{LC}$ when analyzing tap and river waters. As sulfite ions can compete with anionic phenol group on the Dowex 1-X9 precolumn in this system, it must yield lower recoveries of analytes in the water samples. In this study, acidic alumina that can exchange with a weak anionic compound was used for the first time as a prefilter for humic substances. Acidic alumina was expected to prevent the precolumn clogging due to insoluble humic acids in the acidic solution and to adsorb selectively soluble fulvic acids by weak ionic and van der Waals interaction, yet it generally was used to extract analytes as an anionic exchanger in the normal-phase mode (water-free solution). The recoveries of all analytes spiked in tap water samples were obtained after they were filtered with different amounts of acidic alumina and the results were shown in Figure 2.

The reduced matrix peaks provided acceptable recoveries for polar phenolic compounds with up to $0.8 \mathrm{~g}$ of acidic alumina and the recoveries for the other compounds did not decrease. The interfering peaks due to humic substances in the chromatogram of alumina-filtered tap water was slightly smaller than that of unfiltered tap water (see Figure 3). When $1.5 \mathrm{~g}$ of acidic alumina was applied to the filter, the mean recoveries were 


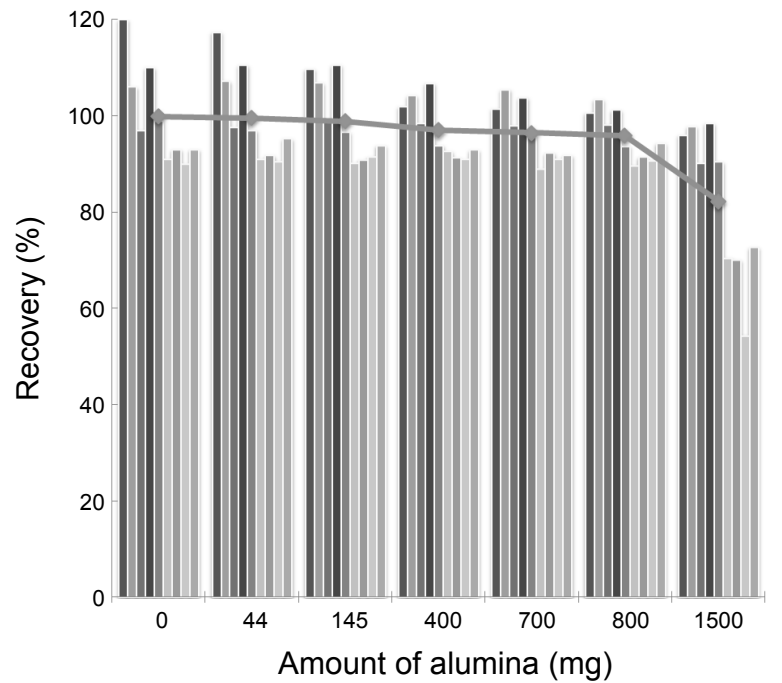

\begin{tabular}{|ll|}
\hline- phenol & 4-chloro- $m$-cresol \\
$-p$-nitrophenol & 4,6-dinitro-o-cresol \\
- o-chlorophenol & 2,4-dichlorophenol \\
- o-nitrophenol & $-2,4,6$-trichlorophenol \\
- 2,4-dimethylphenol & - mean recovery \\
\hline
\end{tabular}

Figure 2. Effect of acidic alumina weight on the recoveries of phenolic compounds.

low, especially for chlorinated phenols.

The calibration curves of this system were studied by the preconcentration of $100 \mathrm{~mL}$ tap water filtered by $0.8 \mathrm{~g}$ of acid alumina. Linearity was observed in the range of $0.2 \sim 5.2 \mu \mathrm{g} / \mathrm{L}$ with $R^{2}$ values of $0.980-0.999$ for all phenolic compounds.

Application to environmental samples. The on-line SPEHPLC method established in this study was applied to tap and river water samples after being filtered with acid alumina. Recovery studies were made with six replicates and sample volumes of $100 \mathrm{~mL}$ spiked with $5 \mu \mathrm{g} / \mathrm{L}$ of each analyte. The results showed mean recoveries of over $90 \%$ and good reproducibility with 2 - $6 \%$ of RSD for all analytes presented in Table 4 . The
Table 4. Recoveries and reproducibilities for tap water and river water

\begin{tabular}{lccccc}
\hline \multirow{2}{*}{ Compound } & \multicolumn{2}{c}{ Tap water } & & \multicolumn{2}{c}{ River water $^{a}$} \\
\cline { 2 - 3 } \cline { 5 - 6 } & $\begin{array}{c}\text { Recovery } \\
(\%)\end{array}$ & $\begin{array}{c}\text { RSD }^{c} \\
(\%)\end{array}$ & & $\begin{array}{c}\text { Recovery }^{b} \\
(\%)\end{array}$ & $\begin{array}{c}\text { RSD }^{c} \\
(\%)\end{array}$ \\
\hline phenol & 101 & 2.78 & & 92.0 & 2.49 \\
$p$-nitrophenol & 103 & 2.74 & & 101 & 3.42 \\
$o$-chlorophenol & 98.1 & 2.08 & & 90.7 & 4.23 \\
$o$-nitrophenol & 101 & 6.18 & & 95.8 & 5.68 \\
2,4-dimethylphenol & 93.7 & 6.08 & & 93.3 & 5.28 \\
4-chloro-m-cresol & 89.7 & 3.98 & & 90.5 & 3.47 \\
4,6-dinitro-o-cresol & 91.4 & 3.91 & & 89.8 & 3.56 \\
2,4-dichlorophenol & 90.7 & 4.03 & & 91.0 & 4.27 \\
2,4,6-trichlorophenol & 94.3 & 3.96 & & 91.7 & 5.05 \\
\hline average & 95.9 & 3.97 & & 92.9 & 4.16 \\
\hline
\end{tabular}

${ }^{a}$ Han river water. ${ }^{b}$ Concentration of compound spiked : $0.5 \mu \mathrm{g} / 100 \mathrm{~mL}$. ${ }^{c} \mathrm{RSD}$ : relative standard deviation $=$ standard deviation $/$ mean $\times 100,(\mathrm{n}=6)$.

Table 5. Comparison of the enrichment factor and pretreatment time between this study and the EPA method

\begin{tabular}{lcc}
\hline & On-line method & EPA method \\
\hline enrichment factor $^{a}$ & 320 & 75 \\
pretreatment time $(\mathrm{min})$ & 50 & 170 \\
\hline
\end{tabular}

${ }^{a}$ (initial volumn $\times$ recovery)/final volume.

chromatograms of the phenolic compounds spiked in tap and river water are shown in Figure 3.

Comparison of the on-line SPE-HPLC method with the EPA 625 standard method. The EPA 625 standard method for phenolic compounds is based on an acid extraction method using solvent extraction. ${ }^{5}$

The comparison of the EPA standard method and the on-line SPE-HPLC method is shown in Table 5 and 6 . Table 5 showed that this method is more efficient than the EPA method in terms of the enrichment cost and pretreatment process.

Table 6 represents the recoveries and detection limit of nine phenols with two methods. The proposed method in this study
(A)

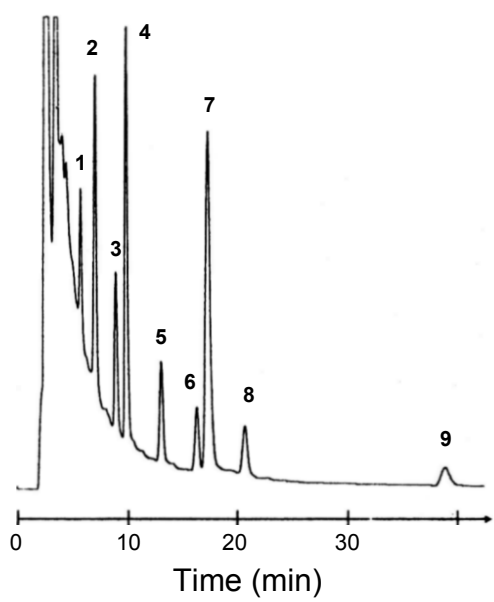

(B)

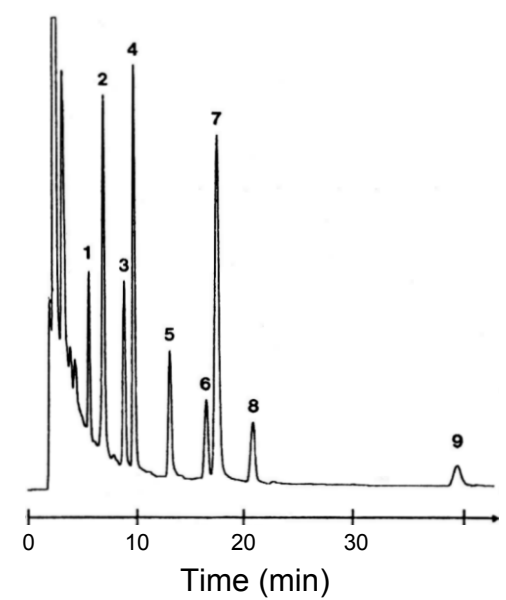

(C)

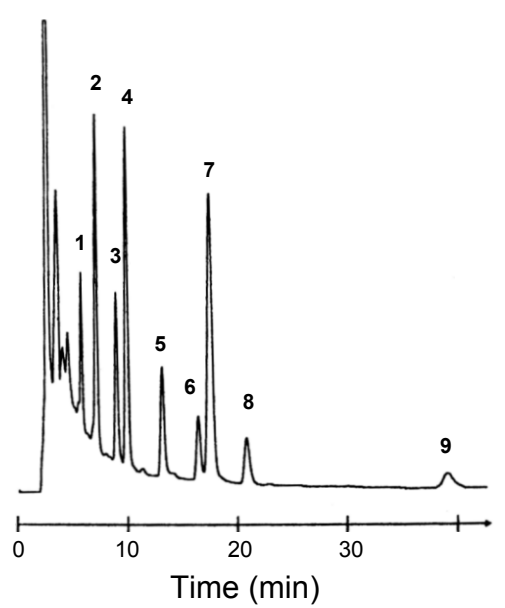

Figure 3. Chromatogram of phenolic compounds spiked in tap and river water. (A) tap water (without alumina filtering). (B) tap water (with alumina filtering); (C) river water (with alumina filtering) Solute: $1=$ phenol; $2=p$-nitrophenol; $3=o$-chlorophenol; $4=o$-nitrophenol; $5=$ 2,4-dimethylphenol; $6=4$-chloro- $m$-cresol; $7=4,6$-dinitro-o-cresol; $8=2,4$-dichlorophenol; $9=2,4,6$-trichlorophenol, Mobile phase: Methanol/Acetonitrile/Water $=22 / 28 / 50(\mathrm{pH} 3)$, Column: Shodex $5 \mu \mathrm{m} \mathrm{C18-5B}(25 \times 4.6 \mathrm{~mm}$ i.d. $)$, Detection: 280 nm, A.U.F.S: 0.08. 
Table 6. Comparison of the Recoveries and Limit of Detection between This Study and the EPA Method

\begin{tabular}{|c|c|c|c|c|}
\hline \multirow{2}{*}{ compound } & \multicolumn{2}{|c|}{$\%$, recovery $^{a}$} & \multicolumn{2}{|c|}{ limit of detection $^{b}$} \\
\hline & EPA & on-line & EPA & on-line \\
\hline phenol & 48.6 & 101 & 1.49 & 0.41 \\
\hline$p$-nitrophenol & 82.2 & 103 & 1.36 & 0.40 \\
\hline$O$-chlorophenol & 40.0 & 98.1 & 1.30 & 0.30 \\
\hline$O$-nitrophenol & 59.6 & 101 & 1.35 & 0.90 \\
\hline 2,4-dimethylphenol & 92.0 & 93.7 & 0.87 & 0.83 \\
\hline 4-chloro-m-cresol & 90.8 & 89.7 & 1.20 & 0.82 \\
\hline 4,6-dinitro- $O$-cresol & 102 & 91.4 & 1.03 & 0.51 \\
\hline 2,4-dichlorophenol & 76.1 & 90.7 & 1.17 & 0.50 \\
\hline 2,4,6-trichlorophenol & 85.4 & 94.3 & 1.10 & 0.53 \\
\hline average & 75.2 & 95.9 & 1.21 & 0.55 \\
\hline
\end{tabular}

${ }^{a}$ Concentration of compound spiked in tap water: $5 \mu \mathrm{g} / \mathrm{L}(500 \mathrm{~mL}$ for the EPA method, $100 \mathrm{~mL}$ for on-line method). ${ }^{b}$ unit: $\mathrm{ppb}(\mu \mathrm{g} / \mathrm{L})$.

showed high recoveries of over $90 \%$. However, the EPA method showed recoveries of below $50 \%$ for volatile phenolic compounds. Detection limits below $0.9 \mathrm{ppb}(\mu \mathrm{g} / \mathrm{L})$ were obtained in the case of the on-line method by $3 \sigma$ method. For the EPA method, the average detection limits were between 0.87 and $1.49 \mathrm{ppb}$. The concentration of the samples with this method at levels 2.4 times lower than the EPA method although sample volume of this method was 5 times smaller than that of the EPA method.

\section{Conclusion}

A on-line SPE-HPLC system for the monitoring of phenolic compounds in aqueous samples was developed. This method allows the selective determination of phenolic compounds at the sub ppb levels in environmental water samples. A significant reduction of determination time was achieved by the on-line combining of sample pretreatment and the analytical HPLC system. In order to decrease the initial interfering peaks due to humic substances, acidic alumina was introduced for the pretreatment process as a filter. As a result, high recoveries and reproducible data were obtained when this method was applied to tap and river water samples. Acidic alumina in the reverse phase mode was the first attempt to filter the humic substance in the water analysis. In addition, the proposed method in this study exhibited superiority to the EPA 625 method in enrichment factor, pretreatment time, recoveries, and detection limit.

Acknowledgments. This work was supported by Hannam University.

\section{References}

1. Neilson, A. H.; Allard, A.-S.; Hynning, P.-Å.; Remberger, M. Toxicol. Environ. Chem. 1991, $30,3$.

2. US Environmental Protection Agency. Sampling and Analysis Procedure for Screening of Industrial Effluents for Priority Pollutants; Environment Monitoring and Support Laboratory: Cincinnati, OH, USA, 1977.

3. Council of the European Communities (2001) Decision 2455/2001/ EC, Off. J. Eur. Commun. 2001, L331, 1.

4. EPA method 604, Phenols in Federal Register, Friday October 26, 1984, Environmental Protection Agency, Part VIII, 40 CFR Part 136, 58.

5. EPA method 625, Base/neutrals and acids in Fed374 era1 Register, Friday October 26, 1984, Environmental Protection Agency, Part VIII, 40 CFR Part 136, 153.

6. Castillo, M.; Puig, D.; Barceló, D. J. Chromatogr. A 1997, 778, 301.

7. Kladi, M.; Dassenakis, M.; Scoullos, M.; Psaroudakis, N. Fresenius Environ. Bull. 2006, 15, 1003.

8. Ou, J.; Hu, L.; Hu, L.; Li, X.; Zou, H. Talanta 2006, 69, 1001.

9. Hyötyläinen, T. J. Chromatogr. A 2007, 1153, 14.

10. Chen, L.; Wang, H.; Zeng, Q.; Xu, Y.; Sun, L.; Xu, H.; Ding, L. J. Chromatogr. Sci. 2009, 47, 614 .

11. Puig, D.; Barceló, D. J. Chromatogr. A 1996, 733, 371.

12. Masqué, N.; Marcé, R. M.; Borrull, F. Trends Anal. Chem. 1998, 17,384 .

13. Lee, D. W.; Kim, J. Y.; Park, Y. H.; Moon, M. H. Anal. Sci. Techinol. 1994, 7(1), 33 .

14. Rodríguez, I.; Llompart, M. P.; Cela, R. J. Chromatogr. A 2000, $885,291$.

15. PhysProp Database. Syracuse Research, Syracuse, NY, USA (http: //www.syrres.com/what-we-do/databaseforms.aspx?id=386).

16. De Llasera, M. P. G.; Rodríguez-Castillo, A.; Vera-Avila, L. E. J. Environ. Sci. Health., Part B 2007, 42, 615.

17. Masqué, N.; Galià, M.; Marcé, R. M.; Borrull, F. J. Chromatogr. A 1998, 803, 147.

18. Masqué, N.; Marcé, R. M.; Borrull, F. J. Chromatogr. A 1998, 793, 257. 